\title{
The Magnitude of Suicidal Behaviour among People Living with Diabetes Mellitus Attending an Outpatient Department of Alamata General Hospital, Mekelle, Tigray, Ethiopia 2019: a Cross-Sectional Study
}

Abreha Tsegay Gebreselassie ( $\nabla$ abrehatsegay@gmail.com )

Mekelle University College of Health Sciences

Workua Mekonen Metekiya

Mekelle University College of Health Sciences

Birhane Gebrehiwot Beyene

Mekelle University College of Health Sciences

Research

Keywords: Suicidal behaviour, Diabetics Mellitus, Ethiopia

Posted Date: May 5th, 2020

DOI: https://doi.org/10.21203/rs.3.rs-26217/v1

License: (1) (i) This work is licensed under a Creative Commons Attribution 4.0 International License.

Read Full License 


\section{Abstract \\ Background}

Globally, suicide accounts $75 \%$ in low and middle-income countries (LMICs). Though the magnitude of suicidal behaviour in high- income countries (HIC) is higher relative to the general population, limited studies had explored about suicidal behaviour among medical outpatients in middle-income countries (LMICs) including this locality. Suicidal behaviours among people with the chronic medical illness are one of the commonest psychiatric emergencies that demand a major health concern by researchers and mental health task forces. People with the chronic medical illness show suicidal ideation and attempt which are fatal problems to end life. Therefore, this study will address the gaps by determining the magnitude of suicidal behaviour among Diabetes Mellitus patients in an outpatient setting of Alamata General Hospital (AGH).

\section{Methods}

Institution based cross-sectional study was conducted among medical patients attending a chronic care clinic in Alamata general Hospital from May to June 2019. A sample of 146 DM patients who were attending an outpatient chronic care clinic was included in the study. Patients' data on sociodemographics, clinical factors, substance use and other information's were collected using a pre-tested structured questionnaire through face to face interview. Suicidal behaviour was used assessed by WHO suicidal behaviour assessment. The collected data were coded, entered and analyzed using frequency, cross-tabulation analysis by SPSS Version 23.

\section{Result}

The magnitude of suicidal behaviour among DM patients at AGH is $30.8 \%$.

\section{Conclusion}

This study demonstrated that suicidal behaviours common problem in diabetic patients was high magnitude.

\section{Background}

Suicide is a fatal act of terminating one's own life and it is a complex process that involves a series of pathways and mechanisms from initiation of ideation, to planning, and finally to attempting suicide (1). Some plan for days, weeks or even years before acting, while others take their lives seemingly impulse without premeditation(2). Suicidal ideation is an important phase in the suicidal process. Preceding 
attempted suicide; which the major risk factors for completed suicide, and is also potentially fatal events $(2,3)$.

Diabetes mellitus is a metabolic disorder of multiple etiological factors characterized by chronic hyperglycaemia with disturbance of carbohydrate, fat and protein metabolism which resulted from either insufficient Insulin secretion, resistance to the action of Insulin or both (4). It is a chronic disease that has become a serious public health problem worldwide (5-7). Several studies support that DM has profound effects on physical and emotional health. Furthermore, DM has been associated with many adverse health effects including reduced life expectancy, increased risk of various complications, decreased quality of life, and even death $(5,7-9)$. On the other hand, it has been reported that patients with chronic medical conditions such as type 2 diabetes mellitus (T2DM) are more likely to manifest psychiatric traits when compared with healthy individuals (10-13). Up to today, the cause and effect relationship between these entities is not clear yet; we do not know whether diabetes increases the risk of psychiatric traits as depression, or whether psychiatric traits increase the risk of diabetes (14-16). It is known that suicidal ideas and suicide attempts occur more frequently in patients with DM than in the general population (6, 17-19). Nonetheless, differences have been reported between patients with type 1 or type II diabetes. For instance, a recent study of people who died by suicide in Finland reported that the proportion of patients with type II diabetes who completed suicide was twice the proportion of patients with type 1 diabetes who completed suicide (20). Other authors indicate that risk factors of suicidal behaviour such as depression, anxiety or hopelessness are present in patients with type 2 diabetes $(11,21)$.

Suicide is an important public health issue; which is the 10th leading cause of death worldwide, a second leading cause of death among those aged 15-29 (22) Suicidal ideation is highly prevalent in the community ranging from 10 to $14 \%$ across a lifetime, 2.3 to $14.6 \%$ within 12 months of the survey and has a close link completed suicide $(2,22)$. An estimated number of more than 804,000 suicide bases occurred worldwide in 2012 and represents $1.8 \%$ of the global burden of disease (23). It is estimated to contribute more than $2.4 \%$ the global burden of disease by the year 2020 and the rate of death due to suicide will be increased to one every 20 seconds(3).

Suicidal ideation and attempt among people with DM had been reported as high as $58.5 \%$ (24) and $13.3 \%$ (25) respectively in the USA. Similarly, suicidal ideation was $51.4 \%$ in South Korea (26), $26.5 \%$ in the USA (27), and $20 \%$, in Australia (28). While the suicidal attempt was $10 \%$ in the USA (29). Suicidal behaviours in DM are higher in those with low-level education, female, gender in the USA (30), alcohol use and cigarette smoking in the USA (31).

Week family and peer relationship, female sex, lack of social support, stigma related to TB, HIV coinfection, substance abuse, depression, duration of the illness, having other comorbid medical illness associated risk factors suicidal behaviour with CMI. $(30,32)$

In Ethiopia magnitude of suicidal ideation and attempt among patients with severe mental illness is shown as;23.3\% for major depression $23.8 \%$ bipolar disorder and $13.1 \%$ for schizophrenia (32). 
Despite the high magnitude of suicidal ideation and attempt among the different chronic medical population in different countries, no data is showing such impact in Ethiopia. Therefore, the aim of the study is to assess the magnitude of suicidal behaviour among patients with DM visiting chronic illness clinic at AGH, Tigray, Ethiopia.

Diabetes Mellitus is one of the most psychologically-demanding chronic diseases, where patients show greater loss of motivation, worse future expectations and a decrease in their quality of life. One study observed that the magnitude of suicidal behaviour in patients with type 2 diabetes was higher than the two-fold observed in the Mexican population ( $11.6 \%$ in patients with diabetes versus $5.2 \%$ in the general population) (33). The results were similar to previous reports showing that diabetes increases the risk of death by suicide $(34,35)$. It was found that suicide attempters with T2DM showed higher levels of blood glucose than those without a history of suicide. Since glucose is the human brain's primary source of cellular fuel, psychological processes such as self-control, decision making, and other emotion regulations depend heavily on intracellular availability of glucose in the brain $(36,37)$. Nevertheless, when performed a logistic regression model, glucose levels did not maintain a statistical significance. It was observed that patients in the suicide attempt group, were younger than the control group $(44.75 \pm 14.01 \mathrm{P}$ $=0.001)$. In this sense, the results showed that younger patients had a three-fold increase in attempted suicide in comparison to the older population. These data indicate that old age can be a protective factor for suicidal behaviour, as suicidal behaviour magnitude decreases with age $(38,39)$. The article suggests that younger individuals have more responsibilities and are under more stress than older individuals (40). Gender may be involved as a possible moderator in suicidal behaviour; for example, a study found a statistical relation between obesity and suicide risk in a group of young adult women, but not in men (41). Another hypothesis is that glucose homeostasis may cause mental disorders (42-43), regardless of the bodyweight; for example, the group of Bendix M. confirmed that higher insulin and lower glucagon plasma levels are associated with SB (44). Then, it is considered that psychological and psychiatric assessments should be performed in diabetic patients before depressive symptoms appear which could prevent suicidal behaviour (45). Also, it is necessary to review studies that have evaluated the use of antidepressants in patients with depression and type 2 diabetes (46). In this sense, a common method of suicide attempt in T2DM patients is the use of high doses of insulin and other medications for treating diabetes $(47,48)$. Therefore, it is supported to have a regular screening and prompt treatment of suicidality, or other psychiatric traits in patients with diabetes (49).

The magnitude of suicide following chronic medical illness varies according to the developmental level of the country, the timing of assessment, sex of victims and classification of chronic medical illness (3). WHO reports shows that an estimated 804,000 suicide death occurred worldwide in 2012, representing an annual global age-standardized suicide rate of 11.4 per 100,000 populations ( 15.0 for male and 8.0 for female). WHO from the general population shows that globally suicides account for $50 \%$ of all violent deaths in men and $71 \%$ in women $(1,3)$. Across sectional study conducted in Korea to assess a one-year magnitude of suicidal ideation in adults older than 20 years of age with DM and depression by taking 17065 subjects. Suicidal ideation was assessed by the self-administered question have you ever had any 
suicidal thought over the past year? And the result shows that $51.4 \%$ of patients had suicidal ideation (26).

Deaths from hanging have increased from 16-24\%. Most of these (suicide) deaths were male in the 20 to 30 years age group. Deaths due to poisoning have increased from $4-28 \%$ over the past 8 years, with males predominating over females. Gunshot related death has also increased from $14 \%$ in 1996 to $25 \%$ in 2000. Over the same period, student enrolment at the University of Transkei has decreased from 7038 in 1996 to 3783 in 2000 , a drop of nearly $50 \%$ (24).

Even though, the magnitude of suicide on the medical patient is not studied more in our finding in Ethiopia study from general population shows high magnitude as follows; cross-sectional survey among 2499 adults, using standardizing, and interview-based measures for suicidality (items on suicide from the CIDI) shows that overall 12-month magnitude of non-fatal suicidal behaviour, consisting of suicidal ideation, plan and attempt was $7.9 \%$ with magnitude significantly higher in the facility sample $10.3 \%$ compared with the community sample $6.3 \%$ (24). Retrospective analysis of mortality patterns from the communicable and non-communicable disease in 43 hospitals of Addis Ababa indicates that, of the total 47,153 samples, about $1.9 \%$ of deaths attributed to suicide (25).

Another cross-section studies conduct in South Korea assessed the one-year magnitude of suicidal ideation in adults older than 20 years of age with both diabetes and depression. it was found that suicidal ideation was higher among those who are older than 50 years of age, less educated, divorce separated \widowed and suffering from a co-morbid medical condition (26). Similar studies South Korea shows that insulin therapy duration diabetes greater than or equal to 5 years of poor glycemic control [FBS $\geq 126 \mathrm{mg} \backslash \mathrm{dl}]$ were significantly associated with suicidal attempt (30).

Suicidal ideation was found higher among females patients $(p=0.002)$ but there was no difference in rates of comorbid infectious between both sexes (30). A history of alcohol abuse, another drug dependency major depression past suicide attempts, and diagnosis of personality disorder have also been associated with suicide risk (30).

\section{Methodology}

\section{Study design and period}

The institution-based cross-sectional study was conducted from May to June 2019 G.C.

\section{Study area}

Alamata is one of the eight weredas in the south Tigray. Located $187 \mathrm{~km}$ by korem line, and $174 \mathrm{~km}$ by mehoni line from Mekelle and $600 \mathrm{~km}$ north from Addis Ababa. The town has 4 zones and 15 ketena. Zone 01 has a total population of $11198(m=5707, f=5491)$ and the total household of 3294 Zone 02 has 
a total population of 18062 (male $=8739$, female $=9323$ ) and the total household of 5312 Zone 03 total population of 16202 (male $=7629$, female $=8573$ ) and the total household of 4765 Zone 04 total population of 17273 (male $=8413$, female $=8860$ ) and the total household of 5080 . The total surface area of the town is 1829.3 hectare. Total population of the town is 62,735 (male $=30,488 \&$ female $=32,247$ ) and Total household is 18,451 with annual increments of the population is $4.61 \%$. It is a lowland area and $1,564 \mathrm{~m}$ above the sea. Annual rainfall in average is $691.5 \mathrm{ml}$ and annual Temperature in $0^{\mathrm{C}}$ from 22 $0^{\mathrm{C}}-260^{\mathrm{C}}$.

Alamata General Hospital is located in zone 02 was founded on 1983E.C Starts as General hospital. It gives service for around 165,205 populations. 82,903(50.2\%) \& females, 82,302(49.8) males reproductive age Female 5043 \& Male 5303.the catchment areas are Alamata town, Alamata rural, Mara region( kobo), Afar region, Bala \& Kukufto. Alamata General hospital has 255 staffs divided in 4 Adult OPDs, 1 under five OPD, 1 IPD, 1 MCH,1 EOPD,1 NICU,1 ART,1Dental OPD,1 Ophthalmic OPD,1 Psychiatry OPD,1 Physiotherapy OPD,1 TB OPD departments.

\section{Source Population}

All DM patients who were attending AGH .

\section{Study Population}

All DM patients who were attending Alamata General Hospital during the study period were included.

\section{Inclusion and exclusion criteria}

\section{Inclusion Criteria}

All DM patients who were 18 years old or above and attending at AGH were included in the study.

\section{Exclusion Criteria}

Those who were seriously ill, under the age of 18 and those with physical disabilities (unable to communicate).

\section{Sample size and sampling procedure}

\section{Sample Size Determination}

The sample size was determined using a single population proportion formula by 
$\mathrm{n}=\left(\underline{\mathrm{z} \alpha / 2)^{2} \mathrm{p}(\mathrm{q})}\right.$

$\mathrm{d}^{2}$

Where $\mathrm{n}=$ sample size

$z=$ confidence interval of $95 \%=1.96$

$d=$ marginal error; 0.05

$\mathrm{n}=1.96^{2}(0.5)(1-0.5) / 0.05^{2}$

$=384$

Since our sample population was less than 10,000 which was 200 we merged it to $\mathrm{Nf}$ using correction formula

$N=200$

$\mathrm{Nf}=\mathrm{n} / 1+\mathrm{n} / \mathrm{N}$

$=384 / 1+384 / 200$

$=132$

Then we added $10 \%$ of the $\mathrm{Nf}$ for non-response rate

$132+14=146$ is the sample size we used to conduct our study

\section{Sampling Techniques}

Convenience random sampling technique was used to select each study participants from the AGH and the data was collected until the quota was full.

\section{Study variables}

Dependent Variable

- Suicidal behaviour.

Independent Variables

I. Socio-demographic factors

- Age, Sex, Religion, Ethnicity, Marital status, Educational status, Occupational status, Residence, Living condition, Income 


\section{Psychosocial factors}

- Social support

- Depression and anxiety

\section{Data collection method and instruments}

The study questionnaire had five components. Socio-demographic characteristics were collected by structured socio-demographic questionnaires. Depression and anxiety were collected by using HADS of seven stage questions and substance-related factors were collected by substance-related questionnaires. Social support was assessed by Oslo-3 item social support scale. It is 3 item questionnaires, commonly used to assess social support and it has been used in several studies,

Outcome variables, suicidal behaviour were assessed by using a structured questionnaire the data was collected by face to face interview. There were 2 data collectors from fourth-year psychiatric nursing students. Data was collected in the AGH from May to June 2019.

\section{Data quality control}

To control the quality of data the questionnaire was designed and modified appropriately. The questionnaire was pre-tested one week before the actual data collection on $5 \%$ (8) of patients at AHC and was not included in the main survey. The data collectors were supervised daily and the field questionnaires were checked daily by the supervisors and principal investigator. When there was any problem the solution was given by discussion with the advisors and data collectors.

\section{Data analysis technique}

Data analysis technique the collected data was analyzed using SPSS 23 software program. For this operation, proper data categorization and coding was used. For the analysis of obtained data simple descriptive statistics (mean, percentage, frequencies, and standard deviation) and cross-tabulation was used to determine the magnitude of suicidal behaviour among DM patients in AGH, Tigray, Ethiopia, 2019 G.C.

\section{Operational definition}

Suicidal behaviour is defined if the respondent ever had either suicidal ideation of attempt,

Suicidal ideation: is defined as if the respondent answers to the question have you ever seriously thought about committing suicide? If yes, the patient has suicidal ideation. 
Suicidal attempt: is defined as if the respondent answers for the question have you ever attempted suicide? If yes, the patient has suicidal attempt,

Depression was assessed Individual who scored $\geq 8$ on depression subscale 7-items by assessing HADS, Anxiety: individual, who scored $\geq 8$ on anxiety subscale 7 -items by assessing HADS,

Social support: The presence of poor social support among medical patients was considered by the sum of Oslo 3-item score of 3-8.

Current users: when individuals or study subjects used specific substances like alcohol, smoking cigarette and khat currently.

Ever users: when study subjects or individuals used specific substances like alcohol, cigarette, and khat even once in their lifetime.

Never users: when study subjects or individuals no use specific substances like coffee, alcohol, cigarette, and khat even once in their lifetime.

\section{Ethical consideration}

Ethical clearance was obtained from the ethical review committee of Mekelle University. A formal letter of permission was obtained from MU and was submitted to AGH. Confidentiality of respondents was maintained. Informed written consent was obtained from each respondent and anyone not willing to take part in the study had full right to do so. Participants in the study who are highly suicidal were referred at the hospital for the assistant.

\section{Dissemination and utilization of a result}

After the data is analyzed, based on the findings obtained, conclusions and recommendations were made. Then the results of the study were submitted to AGH, Mekelle University, College of health science for future planning in routine assessments of mental health particularly suicide for a patient with DM in AGH.. Moreover, the findings of the study disseminated to regional health bureau.

\section{Results}

\section{Socio-demographic characteristics}

The study compromised 146 Diabetic patients; of whom 113(77) were Males. Majority 46(31.5) of the patients were between the age of $46-55$ and mean age was $44.91,100(68.5)$ of them were orthodox Christian followers; 55 (37.7) have finished secondary school; more than half of the participants 79 (54.1 ) were married at the time of the study, nearly $1 / 3$ of them i.e. 45 (30.8) were a private employee; more 
than $3 / 4$ of them i.e. $113(77.4)$ live with their family and most of them $67(45.9)$ earn more than 3000 ETB per month (Table 1).

\section{The magnitude of suicidal behaviour}

Of 146 participants with DM $45(30.8 \%)$ had suicidal behaviour whereas $69.2 \%$ of participants who had not. Out of the study participants who had suicidal behaviour 22(48.88) were above the age of 55 , and 23(51.12) of participants were male, 33(73.3) of them were widowed, 22(48.88) of them had depression, 23(51.12) had anxiety, 33(73.3) of them had poor social support, and all of them i.e. 45(100\%) of them were substance users (Table 2 ).

\section{Discussion}

Suicide is a fatal act of terminating one's own life and it is a complex process that involves a series of pathways and mechanisms from initiation of ideation, to planning, and finally to attempting suicide (1). The finding of this study showed that the overall magnitude of suicidal behaviour among diabetes mellitus patient in Alamata General Hospital was $30.8 \%$, which is within the range of study performed in the USA which was as high as $58.5 \%(24)$ and $13.3 \%(25)$ respectively in the USA. Similarly, our finding was nearly similar to a study performed in the USA which was found to be $26.5 \%$ (27). A cross-sectional study conducted in Korea to assess a one-year magnitude of suicidal ideation in adults older than 20 years of age with DM and depression by taking 17065 subjects. Suicidal ideation was assessed by the self-administered question have you ever had any suicidal thought over the past year? And the result shows that $51.4 \%$ of patients had suicidal ideation (26) which was significantly higher than our finding this might be due to cultural difference, lack of religiosity which is one of a protective factor of suicide, lifestyle and psychosocial stressors. Our finding was significantly different from a finding in Australia which was $20 \%$ and this might be due to better living standard, better management of the illness, less psychosocial stressors compared to Ethiopia. One study observed that the magnitude of suicidal behaviour in patients with type 2 diabetes, $11.6 \%$ in patients with diabetes (33) which is significantly different to our finding and this might be due to difference in the study design which was case-control and it also might be due to the study only includes T2DM patients. Suicidal behaviours in DM are higher in those with low-level education, female, gender in the USA (30), alcohol use and cigarette smoking in the USA (31) which was like our finding.

Another cross-section studies conduct in South Korea assessed the one-year magnitude of suicidal ideation in adults older than 20 years of age with both diabetes and depression. it was found that suicidal ideation was higher among those who are older than 50 years of age, less educated, divorce separated I widowed (26) which is like our finding.

In this study out of female $66.7 \%$ have suicidal behaviour. In this study, $100 \%$ of those who are above 55 years of age have suicidal behaviour. All widowed participants have suicidal behaviour, $67.6 \%$ of uneducated DM patients have suicidal behaviour. Out of those who have poor social support $75 \%$ of 
them have suicidal behaviour, 33\% depressed DM patients of have suicidal behaviour and also $36.3 \%$ of substance users have suicidal behaviour. Out of participants that had suicidal behaviour $15.8 \%$ had suicidal ideation, $14.4 \%$ had a suicidal attempt and $15.1 \%$ of them had the plan to commit suicide.

\section{Conclusion}

This study demonstrated that suicidal behaviour problem in diabetic patients was high magnitude.

\section{Recommendation}

Based on this we recommend

For Tigray Regional Health Bureau; They in addition to medical care provided to DM patients they must have the plan to have mental health service converge like mental health care facility and community care facility that provides services with those who have suicidal behaviour due to DM.

For different organization working in DM \& psychiatric program; they should have the plan to work integrate mental health services with diabetic management and care service. Also, mental health especially suicidal behaviour assessment should be done for diabetic patients.

For Mekelle University College of health science psychiatry unit; they should also provide awareness services to the diabetic patients by giving health education on prevention and treatment services with coordination other responsible body to the higher risk groups to suicidal behaviour like a female, older patients, uneducated, widowed, those who have poor social support and substance users

For researcher; to see in-depth and it needs further study in this idea.

\section{Strengths And Limitations Of The Study}

\section{Strength of the study}

Strength of this study is that the tools we used are standardized and internationally recognized screening tool is used with high reliability to screens suicidal behaviour.

\section{Limitation of the study}

The study, however, could suffer from the following limitations. This study was a cross-sectional study design; it didn't allow establishing a cause and effect of the case.

The study was institution based which could limit it's generalizability to the normal population

\section{Abbreviations}

$\mathrm{AGH}$. .Alamata General Hospital 
$\mathrm{Cl}$. ...Confidence Interval

CIDI...............Compensate International Diagnostic Interview

CMI................Co-morbid medical illness

DM................Diabetes Mellitus

ETB .Ethiopian Birr

GC................Gregorian calendar

HIC................High income

LMIC............. Low and middle income

MU...............Mekelle University

OR............... Odds Ratio

OPD............... Out-Patient Department

SBQR............Suicidal Behavior Questionnaire-Revised

SB.................Suicidal Behavior

SPSS...............Statistical Package for Social Science

WHO..............World Health Organization

WMH.............World Mental Health

\section{Declarations}

\section{Availability of data and materials}

All availability of data and material is attached to the manuscript.

\section{Ethics approval and consent to participate}

This study was carried out after obtaining ethical approval from Mekelle University, College of Health Science office of Health Research Ethics Review Committee (HRERC. Permission letter was gotten from Mekelle University to diabetic clinics, and finally, the letter was disseminated to diabetic professionals, data collectors, who work in the diabetic clinics. Verbal consent was attained from each participant before starting data collection. Study participant had the right to draw from the study at any time and information was recorded anonymously. 


\section{Consent for publication}

Consent of publication for this research is Mekelle University, College of health science, internal medicine and psychiatry department and participants.

\section{Competing interest}

We, three authors, declare that we have no conflict of interest for example on financial funding for scholastic programs, employment or discussion, support from a project sponsor, position and/or rank on advisory board or else type of management relationships and multiple associations.

\section{Funding}

Not applicable for this section but the supposition source of funding is Mekelle University, College of Health Science.

\section{Authors' contributions}

The principal investigator was WM. All authors contributed to the study conception and design. Material preparation, data collection and analysis were executed by WM, AT and BG. The first draft of the manuscript was written by WM and all authors noted on former versions of the manuscript. All authors read and approved the final manuscript.

\section{Acknowledgements}

Our sincere thanks go to Mekelle University College of Health Sciences, department of internal medicine and psychiatry for its provision of the chance to conduct this study. We would like to thank Alamata General Hospital staffs for the information given on diabetic outpatient units and data used for this research, data collectors, and participants without whom this thesis would not be realized.

\section{References}

1. Kapla BJ. Kaplan and saduck's Synopsis of psychiatry. Behavioural Sciences /Clinical psychiatry.Tijdschriftvoorsychiatry 201658 (1); 78-79.

2. LEE J-I M-B, Liao S-C, Chang C-M, Sung S-C, Chiang H-C, Tai C-W. Magnitude of suicidal ideation and associated factors in the general population. J Formos Med Assoc. 2010;109(2):;138-147.

3. Organization WH. Preventing suicide; a global imperative; world health organization; 2014.

4. Fauci B, Longo kaiser. James et al. Harrison's principles of Internal medicine. 17th ed.

5. Batty GD, Kivimaki M, Park IS, Jee SH. Diabetes and raised blood glucose as risk factors for future suicide: Cohort study of 1,234,927 korean men and women. J Epidemiol Community Health. 2012;66:650-2. [CrossRef] [PubMed]. 
6. Jin H, Wu S, Vidyanti I, Di Capua P, Wu B. Predicting depression among patients with diabetes using longitudinal data. A multilevel regression model. Methods Inf Med. 2015;54:553-9. [CrossRef] [PubMed].

7. Sarkar S. Balhara,Y.P.Diabetes mellitus and suicide. IndianJEndocrinol Metab. 2014;18:468-74. [CrossRef] [PubMed].

8. Gylfadottir SS, Christensen DH, Nicolaisen SK, Thomsen RW, Nielsen JS, Itani M, Sindrup S, Jensen TS, Finnerup NB. Painful diabetic polyneuropathy and quality of life in danish type 2 diabetic patients. Scand J Pain. 2017;16:173. [CrossRef] [PubMed].

9. Butwicka A, Frisen L, Almqvist C, Zethelius B, Lichtenstein P, Erratum. Risks of psychiatric disorders and suicide attempts in children and adolescents with type 1 diabetes: A population-based cohort study. Diabetes Care 2015, 38, 453-459. Diabetes Care 2016, 39, 495. [CrossRef] [PubMed].

10. Chung JH, Moon K, Kim DH, Min JW, Kim TH, Hwang HJ. Suicidal ideation and suicide attempts among diabetes mellitus: The korea national health and nutrition examination survey (knhanes IV, V) from 2007 to 2012. J Psychosom Res. 2014;77:457-61. [CrossRef] [PubMed].

11. Conti C, Mennitto C, Di Francesco G, Fraticelli F, Vitacolonna E, Fulcheri M. Clinical characteristics of diabetes mellitus and suicide risk. Front Psychiatry. 2017;8:40. [CrossRef] [PubMed].

12. Davis WA, Starkstein SE, Bruce DG, Davis TM. Risk of suicide in australian adults with diabetes: The fremantle diabetes study. Intern Med J. 2015;45:976-80. [CrossRef] [PubMed].

13. Wang B, An X, Shi X, Zhang JAManagementofendocrinedisease. Suicideriskinpatientswithdiabetes: A systematic review and meta-analysis. Eur J Endocrinol. 2017;177:R169-81. [CrossRef] [PubMed].

14. Foster HD. Suicide and mortality from diabetes. Am J Psychiatry. 1988;145:272. [PubMed].

15. Goldston DB, Kovacs M, Ho VY, Parrone PL, Stiffler L. Suicidal ideation and suicide attempts among youth with insulin-dependent diabetes mellitus. J Am Acad Child Adolesc Psychiatry. 1994;33:240-6. [CrossRef] [PubMed].

16. Handley TE, Ventura AD, Browne JL, Rich J, Attia JR, Reddy P, Pouwer F, Speight J. Suicidal ideationreportedbyadultswithtype1 ortype2diabetes: Resultsfromdiabetesmiles-australia. Diabet Med J Br Diabet Assoc. 2016;33:1582-9. [CrossRef] [PubMed].

17. Igwe MN, Uwakwe R, Ahanotu CA, Onyeama GM, Bakare MO, Ndukuba AC. Factors associated with depression and suicide among patients with diabetes mellitus and essential hypertension in a Nigerian teaching hospital. Afr Health Sci. 2013;13:68-77. [CrossRef] [PubMed].

18. Lofman S, Hakko H, Mainio A, Timonen M, Rasanen P. Characteristics of suicide among diabetes patients: A population based study of suicide victims in Northern Finland. J Psychosom Res. 2012;73:268-71. [CrossRef] [PubMed].

19. Wang Y, Tang S, Xu S, Weng S, Liu Z. Association between diabetes and risk of suicide death: A meta-analysis of 3 million participants. Compr Psychiatry. 2016;71:11-6. [CrossRef] [PubMed].

20. Tabb KM, Perez-Flores $\mathrm{N}$, Wang $\mathrm{Y}$, Huang $\mathrm{H}$. The burden of suicidal ideation among persons with type ii diabetes: A scoping review. J Psychosom Res. 2017;103:113-8. [CrossRef] [PubMed]. 
21. Deschenes SS, Burns RJ, Schmitz N. Comorbid depressive and anxiety symptoms and the risk of type 2 diabetes: Findings from the lifelines cohort study. J Affect Disord. 2018;238:24-31. [CrossRef] [PubMed].

22. Borges G, Nock MK, Abad JMH, Hwang I, Sampson NA, Alonso J, Andrade LH, Angermeyer MC, Beautrais A, Bromet E. Twelve Month Magnitude of and Risk Factors For Suicidal Attempts in The World Mental Health Survey. The Journal of Clinical Psychiatry. 2010;71(12):16-7.

23. Fekadu A, Medhin G, Salamu M, Shiferaw T, Hailemariam M, Rathod SD, Breur E. Non-fatal suicidal behaviour in rural Ethiopia: A cross sectional facility and population based study. BMC Psychiatry. 2016;16(1):75.

24. ROY A,Janal M. Suicide Attempt and Ideation in African- American Diabetic Patients.PSYchiatry Research. 2010; 179 (1); 53-60.

25. Han SJ, Kim HJ, Choi YJ, lee KW, Kim DJ.Icreased risk of suicidal ideation in Korea adults with both Diabet and Depression 2014; 101 (3) e 14-e7.

26. Gold Stone DB, Kelley AE, Reboussin DM, Daniel SS, Smith JA, Schwartz RP. RP, et al. Suicidal ideatipon in ideation and behaviour and non-compliance with medical regimn among diabetic adolescent. Journal of the American academe of child adolescent psychiatry. 1997;36(11):15, 2836.

27. William JBW, Rabkin JG, Remein RH, et al. Multidisciplinary baseline assessment of homosexual men with and without human immunodeficiency virus infection. Arch Gen Psychiatry. 1991;48:12430.

28. Handley T, Ventura A, Browne J, Rich J, Attia J, Reddy P, et al. Suicidal ideation reported by adult with Type 1 and Type 2 diabetes; results from diabetes mellitus - Australia. Diabetic Medicine 2015.

29. Goodwin RD, Kroenke K, Hoven CW, Spitzer RL. Major depression, physical illness, and suicidal ideation in in primary care. Psychosom Med. 2003;65(4):504-5.

30. Shibre T, Hanlon C, Medihn G, Alem A, Kebede D, Teffera S, Kullgren G, Jacobsson L, Fekadu A. Suicidal ideation and attempt in people with severe mental disorders in Butajira, Ethiopia: 10 years follow up of a population-based cohort. BMC Psychiatry. 2014;14(1):150.

31. Scocco p, de Girolomo G, Vilagot G, Alonso J. Magnitude of suicidal ideation, plans, and attempt and related risk factors in Italy; results from the European study on the epidemiology of mental disorders world mental health study comprehensive psychiatry 2008, 49(1); 13-21.

32. ChikezieU,OkogbeninE. Ebuenyil,AwehB; Patterns of comorbid infectious and Associated suicidal ideation among individuals attending HIV/AIDS clinic in Benin city. Epidemiology. 2013;3:/4.

33. INEGI. Estadísticas de Mortalidad. Available online: http://www.inegi.org.mx/saladeprensa/aproposito/ 2017/suicidios2017_Nal.pdf (accessed on 18 January 2017).

34. Wang B, An X, Shi X, Zhang JAManagementofendocrinedisease. Suicide risk inpatients with diabetes: A systematic review and meta-analysis. Eur J Endocrinol. 2017;177:R169-81. [CrossRef] [PubMed]. 
35. Webb RT, Lichtenstein P, Dahlin M, Kapur N, Ludvigsson JF, Runeson B. Unnatural deaths in a national cohort of people diagnosed with diabetes. Diabetes Care. 2014;37:2276-83. [CrossRef] [PubMed].

36. Cohen-Manheim I, Sinnreich R, Doniger GM, Simon ES, Pinchas Mizrachi R, Kark JD. Fasting plasma glucose in young adults free of diabetes is associated with cognitive function in midlife. Eur $\mathrm{J}$ Public Health. 2017;28:496-503. [CrossRef] [PubMed].

37. Mantantzis K, Schlaghecken F, Maylor EA. Food for happy thought: Glucose protects age-related positivity effects under cognitive load. Psychol. Aging 2017, 32, 203-209. [CrossRef] [PubMed].

38. Song HB, Lee,SASocioeconomicandlifestylefactorsasrisksforsuicidalbehavioramongKoreanadults.. J Affect Disord. 2016;197:21-8. [CrossRef] [PubMed].

39. Park S. Jang,H.CorrelationsbetweensuicideratesandthemagnitudeofsuicideriskfactorsamongKorean adolescents. Psychiatry Res. 2017;261:143-7. [CrossRef] [PubMed].

40. Cheah,YK;Azahadi,M, Phang,SN;AbdManaf. ,N.H.Sociodemographic,lifestyleandhealthdeterminants of suicidal behaviour in Malaysia. Psychiatry Res. 2018;261:319-24. [CrossRef] [PubMed].

41. Branco JC, Motta J, Wiener C, Oses,JP;PedrottiMoreira,F, Spessato B. Dias,L.;daSilva,R.Association between obesity and suicide in woman, but not in man: A population-based study of young adults. Psychol. Health Med. 2017;22:275-81. [CrossRef] [PubMed].

42. Dreber $H$, Reynisdottir $S$, Angelin $B$, Hemmingsson $E$. Who is the treatment-seeking young adult with severe obesity: A comprehensive characterization with emphasis on mental health. PLoS ONE. 2015;10:e0145273. [CrossRef] [PubMed].

43. Golomb BA, Tenkanen L, Alikoski T, Niskanen T, Manninen V, Huttunen M, Mednick SA. Insulin sensitivity markers: Predictors of accidents and suicides in Helsinki heart study screenees. J Clin Epidemiol. 2002;55:767-73. [CrossRef].

44. Ozdemir O, Kurdoglu Z, Yildiz S, Ozdemir PG, Yilmaz E. The relationship between atypical depression and insulin resistance in patients with polycystic ovary syndrome and major depression. Psychiatry Res. 2017;258:171-6. [CrossRef] [PubMed].

45. Bendix M, Uvnas-Moberg K, Petersson M, Kaldo V, Asberg M, Jokinen J. Insulin and glucagon in plasma and cerebrospinal fluid in suicide attempters and healthy controls.

Psychoneuroendocrinology. 2017;81:1-7. [CrossRef] [PubMed].

46. Petrak F, Baumeister H, Skinner TC, Brown A, Holt RIG. Depression and diabetes: Treatment and health-care delivery. Lancet Diabetes Endocrinol. 2015;3:472-85. [CrossRef].

47. Myers AK, Trivedi MH. Death by insulin: Management of self-harm and suicide in diabetes management. Curr Diabetes Rev. 2017;13:251-62. [CrossRef] [PubMed].

48. Handley TE, Ventura AD, Browne JL, Rich J, Attia JR, Reddy P, Pouwer F, Speight J. Suicidal ideationreportedbyadultswithtype1 ortype2diabetes: Resultsfromdiabetesmiles-australia. Diabet Med J Br Diabet Assoc. 2016;33:1582-9. [CrossRef] [PubMed].

49. Conti C, Mennitto C, Di Francesco G, Fraticelli F, Vitacolonna E, Fulcheri M. Clinical characteristics of diabetes mellitus and suicide risk. Front Psychiatry. 2017;8:40. [CrossRef] [PubMed]. 


\section{Tables}

Table 1 socio-demographic characteristics of among people living with diabetes mellitus attending an outpatient department of Alamata general hospital, Mekelle, Tigray, Ethiopia $2019(\mathrm{~N}=146)$.

\begin{tabular}{|c|c|c|c|c|}
\hline $\mathrm{S}$ no & Variables & Response category & Frequency & $\%$ \\
\hline \multirow[t]{2}{*}{1} & Sex & Male & 113 & 77.4 \\
\hline & & Female & 33 & 22.6 \\
\hline \multirow[t]{5}{*}{2} & Age & $18-25$ & 12 & 8.2 \\
\hline & & $26-35$ & 22 & 15.1 \\
\hline & & $36-45$ & 44 & 30.1 \\
\hline & & $46-55$ & 46 & 31.5 \\
\hline & & $>55$ & 22 & 15.1 \\
\hline \multirow[t]{2}{*}{3} & Religion & Orthodox & 100 & 68.5 \\
\hline & & Muslim & 46 & 31.5 \\
\hline \multirow[t]{3}{*}{4} & Marital status & Single & 34 & 23.3 \\
\hline & & Married & 79 & 54.1 \\
\hline & & Widowed & 33 & 22.5 \\
\hline \multirow[t]{5}{*}{5} & educational status & Unable to read \& write & 34 & 23.3 \\
\hline & & Able to read \& write & 22 & 15.1 \\
\hline & & Primary school & 25 & 17.12 \\
\hline & & Secondary school & 55 & 37.7 \\
\hline & & Diploma and university degree & 10 & 6.82 \\
\hline \multirow[t]{5}{*}{6} & Occupation & Unemployed & 34 & 23.3 \\
\hline & & Government employee & 45 & 30.8 \\
\hline & & Private employee & 45 & 30.5 \\
\hline & & Farmer & 11 & 7.5 \\
\hline & & Student & 11 & 7.5 \\
\hline \multirow[t]{2}{*}{7} & With whom are you living now & With family & 113 & 77.4 \\
\hline & & Alone & 33 & 22.6 \\
\hline \multirow[t]{4}{*}{8} & Average monthly income & Less than 1000 & 12 & 8.2 \\
\hline & & $1001-2000$ & 55 & 37.7 \\
\hline & & $2001-3000$ & 12 & 8.2 \\
\hline & & Greater than 3000 & 67 & 45.9 \\
\hline
\end{tabular}

Table 2 Magnitude of suicidal behaviour among people living with diabetes mellitus attending an outpatient department of Alamata general hospital, Mekelle, Tigray, Ethiopia $2019(\mathrm{~N}=146)$. 


\begin{tabular}{|c|c|c|c|c|}
\hline \multirow[t]{2}{*}{ S no } & \multirow[t]{2}{*}{ Variables } & \multirow[t]{2}{*}{ Response category } & \multicolumn{2}{|c|}{ Suicidal behaviour } \\
\hline & & & Yes & No \\
\hline \multirow[t]{2}{*}{1} & Sex & Male & $23(20.4$ & $90(79.6)$ \\
\hline & & Female & $22(66.7)$ & 11(33.3) \\
\hline \multirow[t]{5}{*}{2} & Age & $18-25$ & 0 & $12(100 \%)$ \\
\hline & & $26-35$ & 0 & $22(100 \%)$ \\
\hline & & $36-45$ & $11(25)$ & $33(75)$ \\
\hline & & $46-55$ & $12(26.1)$ & $34(73.9)$ \\
\hline & & $>55$ & $22(100 \%)$ & 0 \\
\hline \multirow[t]{2}{*}{3} & Religion & Orthodox & $45(100 \%)$ & 0 \\
\hline & & Muslim & 0 & $46(100 \%)$ \\
\hline \multirow[t]{3}{*}{4} & Marital status & Single & 0 & $34(100 \%)$ \\
\hline & & Married & $12(15.2)$ & $67(84.8)$ \\
\hline & & Widowed & $33(100 \%)$ & 0 \\
\hline \multirow[t]{5}{*}{5} & educational status & Unable to read \& write & $23(67.6)$ & $11(32.4)$ \\
\hline & & Able to read \& write & $11(50)$ & $11(50)$ \\
\hline & & Primary school & 0 & $35(100 \%)$ \\
\hline & & Secondary school & $11(20)$ & $44(80)$ \\
\hline & & Diploma and university degree & 0 & $10(100 \%)$ \\
\hline \multirow[t]{5}{*}{6} & Occupation & Unemployed & $22(64.7)$ & $12(35.3)$ \\
\hline & & Government employee & 0 & $11(100 \%)$ \\
\hline & & Private employee & 0 & $45(100 \%)$ \\
\hline & & Farmer & $11(100 \%)$ & 0 \\
\hline & & Student & $12(26.7)$ & $33(73.3)$ \\
\hline \multirow[t]{2}{*}{7} & With whom are you living now & With family & $34(30.1)$ & 79(69.9) \\
\hline & & Alone & 11(33.3) & $22(66.7)$ \\
\hline \multirow[t]{4}{*}{8} & Average monthly income & Less than 1000 & $12(100 \%)$ & 0 \\
\hline & & $1001-2000$ & $22(40)$ & $33(60)$ \\
\hline & & $2001-3000$ & 0 & $12(100 \%)$ \\
\hline & & Greater than 3000 & $11(16.4)$ & $50(83.6)$ \\
\hline \multirow[t]{2}{*}{9} & Depression & Yes & $22(33.3)$ & $44(66.7)$ \\
\hline & & No & $23(28.8)$ & $57(71.2)$ \\
\hline \multirow[t]{2}{*}{10} & Anxiety & Yes & $22(33.3)$ & $44(66.7)$ \\
\hline & & No & $33(75)$ & $11(25)$ \\
\hline \multirow[t]{2}{*}{11} & Poor social support & Yes & $33(75)$ & $11(25)$ \\
\hline & & No & 12(11.8) & $90(88.2)$ \\
\hline \multirow[t]{2}{*}{12} & Substance use & Yes & $45(36.3)$ & $79(63.7)$ \\
\hline & & No & 0 & $22(100 \%)$ \\
\hline
\end{tabular}


Page 19/19 